\title{
Innovative Research on the Blending Learning Mode of Econometrics
}

\author{
Song Ge1, Zhuang Jian², Zhiqing Xia ${ }^{*}$ \\ ${ }^{1}$ School of Finance, Qilu University of Technology, Jinan 250353, Shandong Province, China; \\ ${ }^{2}$ Linyi Educational Scientific Research and Development Center, Linyi City 276000, Shandong Province, China
}

Funding: The 2019 Ministry of Education industry-university cooperation collaborative education project "Research on the Construction of Economics and Management Professional Data Analysis Laboratory" (Project number: 201902077020).

\begin{abstract}
Due to the outbreak of the Covid-19 in 2020, online education has become the mainstream. After the epidemic, the blending learning mode has also become a key goal of the teaching reform of colleges and universities, and the blending learning mode of various courses has blossomed everywhere. In this context, this paper used the Econometrics course as the carrier, analyzed the many unreasonable problems in the traditional Econometrics course, and proposed an optimization plan and path for the blending learning mode to address these problems.
\end{abstract}

Keywords: Econometrics; Blending learning mode; Teaching innovation

Publication date: April, 2021; Publication online: 30 April, 2021

*Corresponding author: Zhiqing Xia, Ge Song@sina.com

\section{Introduction}

At the beginning of 2020, the sudden outbreak of the Covid19 has made the teaching development of higher education in China face sudden challenges. Under the requirements of the Ministry of Education to "suspend classes without stopping teaching and learning", colleges and universities have carried out comprehensive online teaching on a large scale. However, the "offline teaching" after resuming school should not only be a mechanical repetition of the original teaching content, but should be an effective expansion and bold innovation based on the results of "online teaching". In order to ensure and deepen the results of "online teaching" and complete the reasonable connection of "online and offline" classes after resuming, this paper took the Econometrics course as an example to explore the new mode of blending learning of Econometrics and optimize the curriculum construction.

\section{Current problems in the teaching of}

\section{Econometrics}

\subsection{The teaching mode is too traditional}

At present, the Econometrics courses in most colleges and universities still follow the teaching method based on teachers, which is related to the characteristics of this course. The study of Econometrics is based on statistics, mathematical economics, and western economics, and its theoretical content contains more mathematical formulas and models. Under this circumstance, it is relatively simple and feasible for teachers to cooperate with the application of writing on the blackboard to carry out traditional cramming teaching. However, if the teaching method is used blindly, it will be difficult for students to strengthen their understanding of knowledge points, and teachers cannot get timely feedback on the students' knowledge mastery, and conduct targeted or differentiated teaching in time. Moreover, a teacher-oriented classroom will make the atmosphere dull, and the students' enthusiasm for learning will decrease day by day, which will eventually lead to low understanding of students and loss of interest in the course.

\subsection{Teaching content emphasizes theory over practice}

Econometrics is a highly practical and professional core course, which can provide help for students' thesis practice or postgraduate study. However, currently subject to credit 
restrictions, this course is set up in the first semester of the junior year, with a total of 56 class hours (40 theoretical class hours +16 computer class hours). It is difficult for students to fully grasp the basic theoretical knowledge in an effective time, and practical learning is restricted by the network and equipment. It can only be completed in the laboratory during the experimental class time, and the experimental subjects are limited to the existing sample questions given in the textbook, which are often old and lack the timeliness of analysis of current economic problems. These problems have resulted in the teaching and learning status quo of Econometrics that emphasizes theory but not practice. Teachers should not only focus on explaining theoretical knowledge in class, but should guide students from their perspective to discover social and economic problems and establish econometric models to analyze and solve problems. And the ultimate goal should be to help students learn how to analyze economic data independently, master the idea of interpreting model conclusions, and cultivate students' ability to use econometric models to analyze problems flexibly, rather than simply memorizing related theories of econometric models.

\subsection{The assessment method is unreasonable}

In the traditional Econometrics course assessment, more than $70 \%$ of the scores are determined by the final exam results, which is a traditional, extremely single, and unreasonable assessment method. It can only examine students' understanding of theoretical knowledge, but fails to examine students' practical ability, so it is contrary to the original intention of this course. The learning goal of Econometrics is to master the methods of analyzing economic data, cultivate the ability to objectively analyze economic phenomena, and have the ability to build models independently, and to test, modify, interpret, and predict models. It has a strong practical guiding significance, rather than simply memorizing formulas and models. Obviously, the final exam alone cannot achieve the purpose of testing learning goals.

\section{Literature analysis of blending learning mode}

Blending Learning is a form of "online" + "offline" teaching that combines the advantages of online teaching and traditional teaching. Through the effective combination of the two teaching methods, students can learn from the shallower to the deeper. In other words, blending learning can give full play to the autonomy of teachers and students, and can fully reflect the initiative, enthusiasm and creativity of students as the main body of the learning process.
There is no unified mode for the implementation of blending learning, but there is a unified pursuit, that is to give full play to the advantages of both "online" and "offline" teaching, transform the traditional teaching, change the teacher's over-reliance on teaching in the teaching process, which leads to low learning initiative, insufficient participation, and large differences in the learning results of different students.

Kekang $\mathrm{He}^{[1]}$ (2004) believed that blending learning effectively combines the advantages of face-to-face learning with the advantages of E-learning, which can not only give full play to the leading role of teachers in teaching, but also give full play to students' independent learning and selfmanagement ability. Jiahou $\mathrm{Li}$ translated the concept of "blending learning" into "integrated learning", emphasizing that blending learning is to integrate various teaching elements such as teaching methods, modes and ways, in order to achieve the optimal combination of teaching elements. Kedong Li et $\mathrm{al}^{[2]}$ (2004) analyzed the theoretical basis, basic principles and application modes of blending learning, and designed eight steps of blending learning as follows: determination of the goal of blending learning, determination of the expected performance, selection of the delivery channels and media, study design, supportive strategy, planned action observation, study evaluation and revision study. Manli Sun ${ }^{[3]}$ (2015) conducted a research on the blending learning mode of foreign universities, and conducted a more comprehensive explanation and analysis on the production and development, connotation and characteristics, organization and design, advantages and challenges, and development conditions of blending learning modes. Yiqiong Chen $^{[4]}$ (2020) believed that in the context of "Internet +", using the advantages of online teaching can stimulate students' interest in learning, broaden their knowledge horizons, effectively test students' learning effects, and improve the teaching effect essentially.

\section{The optimized path of the blending learning mode of Econometrics}

The ultimate goal of developing blending learning is not to use online platforms, not to build digital teaching resources, nor to carry out tricky teaching activities, but to effectively enhance the depth of learning for most students. Combining the characteristics of the econometrics course and the professional characteristics of the economics-related majors that this course is oriented towards, blending learning can be 
tried from the following aspects:

3.1 To build online resources to realize the explanation of basic theoretical knowledge

The blending learning allows teachers to teach and students to learn in different places and different times, breaking the limitations of learning time and space. The core value of online teaching platform construction is to expand the time and space of teaching and learning. Econometrics is a subject that focuses on experimentation and practice, and case teaching and practical teaching are indispensable parts. Through reasonable use of online resources, students can better complete cases and practical exercises without wasting valuable time in class. Take the Econometrics of our school as an example. At present, our school uses the "website of Chinese University MOOC + MOOC Class + WeChat Group" model, in which teachers upload corresponding teaching plans, teaching videos, and related auxiliary videos, set up weekly homework and practical tasks and case discussion areas, and set score weights according to the setting of the syllabus, and student's complete online tasks in a task-driven manner and obtain corresponding scores to form a systematic teaching-learning link.

3.2 To teach, resolve doubts, examine, consolidate, and transform online learning through the offline way

The main tasks of offline courses are mainly two parts: first, explain the key and difficult points of the course in face-toface lectures, and establish study groups; teachers and students participate in exchanges and discussions, and each group summarizes the key content or problems, and feeds the content back to teachers; teachers give specific explanations to the question points. Second, complete the practical tasks in groups and publish the results of the tasks. Students can exercise their teamwork ability through offline practice.

\subsection{To joint the online and offline assessment}

The teaching method has changed, so the assessment method of student performance should also be changed accordingly, from the assessment method that emphasizes examination and theory to the method of "taking theoretical examination as the main, the practical examination as supplemented, and the daily performance as the basis". The specific classification can be divided into theoretical assessment and practical assessment according to different assessment content, online assessment and offline assessment according to different assessment methods, and regular assessment and final assessment according to the time of assessment. The specific score weights are shown in Table 1 below. In the after-school homework and final exams, the proportion of the two is $50 \%$. The assessment content is more inclined to the basic assumptions of a linear regression, multiple linear regression, and classical least squares, as well as the definition of several situations that violate the assumptions and the explanation section of the revised ideas; Case discussions, practice reports and group publications account for $40 \%$ of the total, which is more inclined to the practice part of chapters such as heteroscedasticity, autoregression, endogeneity, and multicollinearity. By increasing the proportion of scores, students' ability to discover and solve problems can be cultivate.

Table 1. Distribution table of assessment scores

\begin{tabular}{|c|c|c|c|c|c|c|}
\hline \multirow[b]{2}{*}{$\begin{array}{l}\text { assessment } \\
\text { form }\end{array}$} & \multicolumn{2}{|c|}{ Online assessment } & \multicolumn{4}{|c|}{ Offline assessment } \\
\hline & $\begin{array}{l}\text { case } \\
\text { discussions }\end{array}$ & $\begin{array}{l}\text { practice } \\
\text { reports }\end{array}$ & final exams & $\begin{array}{l}\text { group } \\
\text { publications }\end{array}$ & $\begin{array}{l}\text { after- } \\
\text { school } \\
\text { homework }\end{array}$ & $\begin{array}{l}\text { attendance } \\
\text { rate }\end{array}$ \\
\hline scores & 10 & 20 & 40 & 10 & 10 & 10 \\
\hline
\end{tabular}

\section{References}

[1] He KK. Looking at the new development of educational technology theory from Blending Learning (top, bottom)[J]. Audio-visual Education Research, 2004(3): 1-6.

[2] Li KD, Zhao JH. The principle and application mode of blended learning $[\mathrm{J}]$. Audio-visual Education Research, 2004(7): 1-6.
[3] Sun ML. A review of blended learning teaching models in foreign universities[J]. Journal of Fujian Normal University. Philosophy and Social Sciences Edition, 2015 (3): 153-160.

[4] Chen YQ. Research on Teaching Optimization of "Econometrics" under the Internet + Background[J]. Business Education, 2020(25): 120-121. 